hindering the assumption of a coplanar configuration and hence the resonance of the external double bond with the nucleus.

The most remarkable manifestation of this effect is the greatly reduced tendency of this hydrocarbon to polymerize, which was first noticed by Klages ${ }^{4}$. It has been found to undergo no measurable change in two weeks at $100^{\circ} \mathrm{C}$., whereas the polymerization of styrene and other nuclear-methylated homologues containing at least one unsubstituted position orthoto the vinyl - group is about 90 per cent complete after two or three days at this temperature. Polymerization to an extremely brittle polymer of low molecular weight was effected by heating at $190^{\circ} \mathrm{C}$. for several days, and also at room temperature in the presence of about 1 per cent of stannic chloride as catalyst.

Since 2,6-dichloro-styrene has been reported to polymerize readily ${ }^{5}$, it is possible that some electronic interaction, such as the reversed field effect of the ortho-methyl - groups ${ }^{6}$, is also of importance in causing the stability of vinyl-mesitylene.

There is a close analogy in steric terms between vinyl-mesitylene and $\alpha$-methyl-styrene, for, in the former, the relevant rotation is hindered by the two ortho-methyl - groups, and in the latter the two orthohydrogen atoms interfere with the methyl - group on the rotating propenyl - group. This analogy extends to the physical properties and polymerization characteristics of the two compounds?

We are indebted to Dr. H. W. Thompson for the infra-red measurements, and to the directors of Trinidad Leaseholds, Ltd., for permission to pubiish this note ; a full account of the work will be published elsewhere.

$$
\begin{aligned}
& \text { F. R. BUCK } \\
& \text { G. T. KenNedy } \\
& \text { F. MoRTON } \\
& \text { E. M. TANNER }
\end{aligned}
$$

Trinidad Leaseholds, Limited, Central Laboratory, King's Langley, Herts.

March 30.

${ }^{1}$ Adams, R., and Theobald, C. W., J. Amer. Chem. Soc., 65, 2383 (1943).

${ }^{2}$ O'Shaughnessy, M. T., and Rodebush, W. T., J. Amer. Chem. Soc., 62, $2906(1940)$.

${ }^{3}$ Brown, W. G., and Reagan, H., J. Amer. Chem. Soc., 69, 1032 (1947).

- Klages, A., Ber., 35, 2245 (1902).

${ }^{5}$ Marvel, C. S., et al., J. Amer. Chem. Soc., 68, 861 (1946).

${ }^{6}$ Kenner, J., and Morton, F., J. Chem. Soc., 679 (1934).

'Cf. Hersberger, A. B., Reid.' J. C., and Heiligmann, R. G., Ind. Eng. Chem., 37, 1073 (1945).

\section{Electric Dipole Moments of Some Styrenes}

THE electric dipole moments, in benzene solution at $25^{\circ} \mathrm{C}$., of the following nuclear methylated styrenes have been measured :

(I) $p$-methyl-styrene

(II) $m$-methyl-styrene

$0 \cdot 38 \pm 0 \cdot 1 \mathrm{D}$

(III) 2,4,5-trimethyl-styren

$0 \cdot 36 \pm 0 \cdot 1 \mathrm{D}$

$0.45 \pm 0.1 \mathrm{D}$

(IV) 2,4,6-trimethyl-styrene $0.42 \pm 0.1 \mathrm{D}$

These values are approximately corrected for atom polarization. Otto and Wenzke ${ }^{1}$ report a value of $0.63 D$ for $(I)$. The others appear not to have been examined.

The moment of toluene is $0.35 D$ in the gas phase, corrected for atom polarization ${ }^{2}$; so the values found for (I), (II) and (III) are consistent with the moment of styrene being very small, and with there being very little induction of a moment in the vinyl-grouping by the $o$-methyl - group in (III). Direct measurements on styrene leave uncertainty about its moment; but this is probably not greater than $0.37 D^{1,3,4,5}$.

The moment of (IV) is therefore larger than is consistent with the other values. The most obvious cause of this anomaly (see preceding communication; cf. Hampson and co-workers $)^{6}$ is that in (IV) the o-methyl - groups prevent the vinyl - group assuming a configuration co-planar with the benzene ring, as it would need to do to be in the best position for forming $\pi$-bonds therewith.

This explanation implies that the moment of the styrene molecule in which $\pi$-bonding is prevented may be as large as $0.4 D$, though there is no evidence as yet to show which pole is nearer to the benzene ring.

If this be so, then whichever is the direction, the moment is different from that actually found for styrene, and this indicates that the $\pi$-bonding in the latter causes a moment which may be $c$. +0.1 to +0.4 , or -0.4 to $-0.7 D$; that is, there is a permanent electron drift tending to cause either ortho-, para- or meta - direction in the ring. The latter seems to us unlikely, but until the direction of the moment of (IV) has been established, no certain answer can be given to this question.

A further implication is that in the 'inhibited' styrene either the $\sigma$-bond skeleton is polar, or the moment of the $\mathbf{C}-\mathbf{H}$ bond is different in benzene and in ethylene, or both are true.

There appears also to be a difference between the moments of styrene and of triphenylethylene $\left(0.6 \mathrm{D}^{3}\right)$, which may arise in the same way.

We are indebted to Mr. G. T. Kennedy for bringing this problem to our notice, and for supplying the compounds.

K. B. Everard

L. E. SutTon

Physical Chemistry Laboratory, Oxford.

March 30.

${ }^{1} J$. Amer. Chem. Soc, , 57, 294 (1935).

${ }^{2}$ Smyth, C. P., and McAlpine, K. B., J. Amer. Chem. Soc., 55, 453 (1933). ${ }^{3}$ Smyth, C. P., and Dornte, R. W., J. Amer. Chem. Soc., 53, 1296

${ }^{4}$ Lee, S., J. Soc. Chem. Ind., Japan, 43, 190 (1940).

${ }^{5}$ Hannay, N. B., and Smyth, C. P., J.Amer. Chem. Soc., 68, 244 (1946).

J. Chem. Soc., 10 (1937); 981 (1939).

\section{Titration Curves of Hydrogen Micas}

THE titration curves of a number of micas have been studied as a part of a scheme of work on the electrochemistry of structurally well-known crystals in finely ground states. Some typical results obtained with muscovite are given below. Details will be published elsewhere.

The finely ground material having particles with 'equivalent spherical diameters' smaller than $\mathbf{2 \cdot 0}$ microns was leached with dilute hydrochloric acid to obtain the hydrogen- or acid-mica by the replacement of the exposed potassiums by hydrogen ions. Potentiometric titration curves of hydrosols of this hydrogen mica with bases show three inflexions, the first of which is often very weak while the other two are quite prominent. The $p H$ values at the inflexions as well as the form of the titration curve depend, to some extent, on the nature of the base used. Titration with sodium or potassium hydroxide gives the first inflexion at a $p H$ between $6 \cdot 15$ and 